\title{
Lumbar Spondylolisthesis in Rheumatological Practice in Lome (Togo): Frequency and Semiological Profile
}

\author{
Cyrille Komi Tagbor ${ }^{*}$, Viwale Etonam Sika Koffi-Tessio², Prenam Houzou ${ }^{3}$, Eyram Fianyo1, \\ Kodjo Kakpovi ${ }^{4}$, Kokou Hefoume Amegan-Aho5, Sadat Oniankitan'2, Awaki-Esso Atake², \\ Victor Adjenou', Owonayo Oniankitan'2, Moustafa Mijiyawa²
}

\author{
${ }^{1}$ Rheumatology Department, Be Hospital, Lome, Togo \\ ${ }^{2}$ Rheumatology Department, Sylvanus Olympio Teaching Hospital, Lome, Togo \\ ${ }^{3}$ Rheumatology Department, Kara Teaching Hospital, Kara, Togo \\ ${ }^{4}$ Rheumatology Department, Tomde Regional Hospital, Kara, Togo \\ ${ }^{5}$ Paediatric Department, Ho Teaching Hospital, Ho, Ghana \\ ${ }^{6}$ Clinic Autel d'Elie, Lome, Togo \\ Email: ^tcyrille18@yahoo.ca
}

\begin{abstract}
How to cite this paper: Tagbor, C.K., KoffiTessio, V.E.S., Houzou, P., Fianyo, E., Kakpovi, K., Amegan-Aho, K.H., Oniankitan, S., Atake, A.-E., Adjenou, V., Oniankitan, O. and Mijiyawa, M. (2022) Lumbar Spondylolisthesis in Rheumatological Practice in Lome (Togo): Frequency and Semiological Profile. Open Journal of Rheumatology and Autoimmune Diseases, 12, 21-28. https://doi.org/10.4236/ojra.2022.121003
\end{abstract}

Received: October 17, 2021

Accepted: January 3, 2022

Published: January 6, 2022

Copyright $\odot 2022$ by author(s) and Scientific Research Publishing Inc. This work is licensed under the Creative Commons Attribution International License (CC BY 4.0).

http://creativecommons.org/licenses/by/4.0/ (c) (i) Open Access

\begin{abstract}
Objectives: To determine the frequency, the clinical and radiological features of lumbar spondylolisthesis in a rheumatological practice in Lomé. Patients and methods: This was a cross-sectional study conducted in the rheumatology department of the Sylvanus Olympio Teaching Hospital in Lomé between January 1997 and December 2019. Medical records of patients with symptomatic spondylolisthesis with radiographic confirmation were reviewed. The Meyerding classification system was used for grading. Results: Of the $350 \mathrm{pa}-$ tients contacted, 118 consented to participate in the study, making a response rate of $33.71 \%$. Of the $118,104(88.1 \%)$ were females. 109 (92.4\%) presented with radicular pain and $9(7.6 \%)$ presented low back pain. The mean age of the patients was $54.24 \pm 11.19$ years. The average duration of the pain was $4.56 \pm 1.32$ years. The spondylolisthesis level most involved was the L4 - L5 (92/118), followed by L5 - S1 (23/118). 106 (89.8\%) patients had anterolisthesis only, seven (5.9\%) combination anterolisthesis and retrolisthesis. The spondylolisthesis was associated with spondylosis in 110 (93.2\%) patients. Spondylosis was found at level L4 - L5 in 38.98\% patients, followed by L5 - S1 (24.58\%), L3 - L4 (18.64\%). Grade I slip was found in 108 (91.53\%) patients and Grade II slips 10 (8.47\%). Isthmic lysis was found in 40 (33.9\%) patients and it was located at L4 in 30 (75.0\%). Conclusion: Lumbar spondylolisthesis appears to be expected in Lomé patients with nonspecific back pain and mainly affects females.
\end{abstract}




\section{Keywords}

Low Back Pain, Spondylolisthesis, Sub-Sahara Africa, Togo

\section{Introduction}

Spondylolisthesis is the slippage of one vertebral body, with its pedicles, transverse and superior articular processes with respect to the adjacent vertebral body [1]. It may remain asymptomatic and only diagnosed accidentally, but often, it causes excruciating low back pain by fatigue and sciatica [1]. Sometimes, there may be lumbosacral radiculopathy syndrome and spinal stenosis in long term [1]. Conventional radiography is the first-line investigative approach in diagnosing degenerated discopathy since it is easy to do, cost less, and provides valuable information [2]. Spondylolisthesis is common, affecting $3 \%$ to $5 \%$ of the world population [2]. Degenerative lumbar spondylolisthesis is a common cause of low back pain, affecting about $11.5 \%$ of the United States population [3]. The prevalence is 6\% in France, with the black population being affected the most [4]. There are limited published studies on spondylolisthesis in Africa despite the importance of the pathology. In Togo, spondylolisthesis is a risk factor for lumbar spinal stenosis in $3.2 \%$ of the cases [5]. This study was undertaken to add to the limited published local data on lumbar spondylolisthesis. The primary purpose of this study was to determine the frequency, the clinical and radiographic features of lumbar spondylolisthesis in Togolese patients.

\section{Patients and Methods}

A cross-sectional study conducted on the medical records of patients with symptomatic spondylolisthesis with radiographic confirmation diagnosed between January 1997 and December 2019 in the Rheumatology department of the Sylvanus Olympio Teaching Hospital and at the Clinic Autel d'Elie, in Lome, Togo. All out-patients and in-patients at admission in the rheumatology department who suffered from non-specific low back pain and had performed x-ray showing spondylolisthesis during the study period were included. All patients suffering from non-specific low back pain without radiography; and patients with radiography and who were unable to perform the new digital radiography at Clinic Autel d'Elie were excluded. The medical records were reviewed for patients' clinic identification and telephone numbers, demographics, date of symptom onset, date of initial presentation, pain characteristics, and physical examination findings, and radiography features (forms, types, grades, and presence of isthmic lysis and discopathy).

Firstly, a total of 450 patients with non-specific low back with or without spondylolisthesis on plain $\mathrm{x}$-ray were selected. Of the 450 patients only patients, only 350 patients had available telephone contact and were called to participate in the study. Secondly (fundraisings), project work requests for financial support 
were duly drafted and sent to the various state companies in the country. Of the 350 patients contacted by telephone, only 118 (33.71\%) were finally studied. The 118 patients were asked to undergo digital radiography within three months in the Clinic Autel d'Elie a private clinic specialized in medical imaging and located 14 miles from the Sylvanus Olympio Teaching Hospital. The same radiologist reviewed all images to ensure uniformity in interpretation. The study covered all expenses. The Meyerding classification system was used for grading [6] [7]. The data was collected using Epi info7.0, and statistical analysis was performed using STATA/IC 11.0

This research was approved by the ethics committee affiliated to the teaching hospitals and the Director of the Sylvanus Olympio teaching hospital. Patients' verbal consent was required before the publication.

\section{Results}

\subsection{General Characteristics of the Population Studied}

Of the 118 patients studied, 104 were females (88.14\%) and 14 males (11.86\%). The sex ratio was 0.13 . The mean age of the patients at the time of digital radiography was $54.24 \pm 11.19$ years (range: 27 and 76 years). The mean age of the patient at the onset of pain was $49.13 \pm 12.38$ years.

\subsection{Clinical Characteristics of the Studied Population}

Radicular pain was the most typical symptom (109/118 patients) (Table 1). The

Table 1. Clinical features of the patients.

\begin{tabular}{lcc}
\hline & Low back pain & Radicular pain \\
\hline Complaints: ${ }^{\star} \mathrm{n}(\%)$ & $9(7.63)$ & $109(92.37)$ \\
Bilateral radiating pain & $0(0)$ & $82(69.49)$ \\
Topography of the pain & & \\
$\quad$ Sciatic nerve L5 & $0(0)$ & $47(39.83)$ \\
$\quad$ Sciatic nerve S1 & $0(0)$ & $29(24.58)$ \\
$\quad$ unwell systematise nerve & $0(0)$ & $23(19.49)$ \\
$\quad$ Crural nerve L4 & $0(0)$ & $5(04.24)$ \\
Profession obligating prolonged sitting: $\mathrm{n}(\%)$ & $2(1.69)$ & $66(55.93)$ \\
Presence of paresthesia: $\mathrm{n}(\%)$ & $2(1.69)$ & $95(80.51)$ \\
Existence of claudication: $\mathrm{n}(\%)$ & $6(5.08)$ & $24(20.34)$ \\
Body mass Index [18.5 - 29]: $\mathrm{n}(\%)$ & $8(6.78)$ & $66(55.93)$ \\
Average Schöber test: $\left({ }^{*} \mathrm{~m} \pm \mathrm{SD}\right)$ & $10 \pm 4,37$ & $10 \pm 4,36$ \\
Presence of hyperlordosis: $\mathrm{n}(\%)$ & $1(0.85)$ & $28(23.73)$ \\
Presence of sphincterian disturbances: $\mathrm{n}(\%)$ & $0(0)$ & $40(33.90)$ \\
Presence of hypoesthesia: $\mathrm{n}(\%)$ & $0(0)$ & $8(6.78)$ \\
\hline
\end{tabular}

${ }^{\star} \mathrm{n}(\%)$ : number (percentage) ${ }^{\star *} \mathrm{~m} \pm \mathrm{SD}$ : mean \pm Standard deviation. 
mean duration of the pain was $4.56 \pm 1.32$ years ( 4.56 years for females and 4.3 years for males). The characteristics of the pain were mechanical in 102 patients (86.4\%), mixed in 10 patients (8.5\%), and inflammatory in the remaining 6 (5.1\%) patients. The mean walking distance was $395.29 \pm 372.71$ meters. The mean height of the patients was $1.6 \pm 0.08$ meters (female: $1.58 \pm 0.8$ meters and male: $1.7 \pm$ 0.7 meters). The average weight of the patients was $73.53 \pm 15$ kilograms (female: $73.6 \pm 15.44$ kilogram and male: $73.07 \pm 11.76$ kilograms).

\subsection{Radiographic Characteristics of the Study Population}

One hundred six patients (89.83\%) presented with antero-listhesis (Table 2). Of those 106 patients, 95 (89.62\%) were females and 11 (10.38\%) males. Of the 118 patients with spondylolisthesis (Figure 1), 40 (33.9\%) had isthmic lysis of which were females $32(80 \%)$ and males $8(20 \%)$. Among the 40 patients with isthmic lysis (Figure 2), 35 (80\%) patients experienced radicular pain and the remaining $5(20 \%)$ low back pain. Spondylosis was seen on the digital radiography of 110 (93.22\%) patients out of the 118 patients with spondylolisthesis. The mean angle of inclination of the sacral plate was $41.66 \pm 12.2$ degrees.

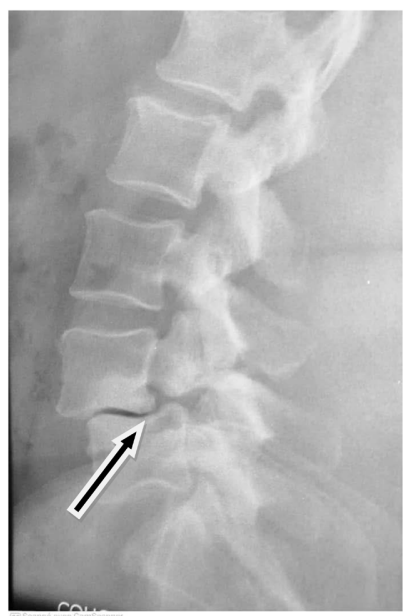

Figure 1. Lateral radiography of lumbar spine showing Grade I spondylolisthesis of L4 - L5.

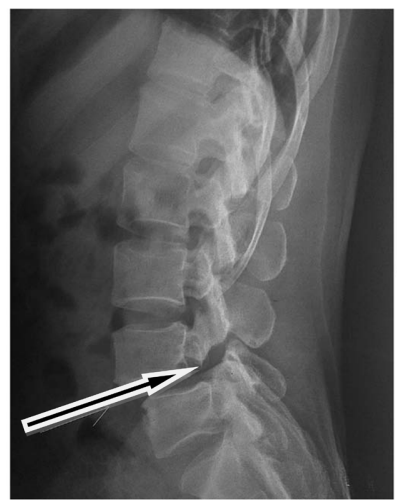

Figure 2. Lateral radiography of lumbar spine showing L5 isthmic lysis. 
Table 2. Radiographic features of the patients.

\begin{tabular}{|c|c|c|}
\hline & Number & Percentage \\
\hline \multicolumn{3}{|l|}{ Form of spondylolisthesis } \\
\hline Anterolisthesis & 106 & 89.83 \\
\hline Anterolisthesis and retrolisthesis & 7 & 5.93 \\
\hline Anterolisthesis and laterolisthesis & 3 & 2.54 \\
\hline Retrolisthesis & 2 & 2.54 \\
\hline \multicolumn{3}{|l|}{ Grade of spondylolisthesis } \\
\hline Grade I & 108 & 91.53 \\
\hline Grade II & 10 & 08.47 \\
\hline \multicolumn{3}{|l|}{ Location of the spondylolisthesis } \\
\hline${ }^{\star} \mathrm{L} 4-\mathrm{L} 5$ & 92 & 77.97 \\
\hline $\mathrm{L} 5-{ }^{* *} \mathrm{~S} 1$ & 23 & 19.49 \\
\hline L3 - L4 & 3 & 2.54 \\
\hline \multicolumn{3}{|l|}{ Location of the isthmic lysis } \\
\hline $\mathrm{L} 4$ & 30 & 25.42 \\
\hline L5 & 8 & 6.78 \\
\hline L4 and L5 & 2 & 1.69 \\
\hline \multicolumn{3}{|l|}{ Spondylosis } \\
\hline L4 - L5 & 46 & 38.98 \\
\hline L5 - S1 & 29 & 24.58 \\
\hline L3 - L4 & 22 & 18.64 \\
\hline L2 - L3 & 8 & 06.78 \\
\hline L1 - L2 & 5 & 04.24 \\
\hline
\end{tabular}

${ }^{\star}$ L: Lumbar vertebrae, ${ }^{\star * S}$ : Sacral vertebrae.

\section{Discussion}

In this study, we described the clinical and radiological semiology features of lumbar spondylolisthesis in 118 Togolese patients. Similar studies are scanty in Sub-Saharan Africa. In this study, there was a female predominance (sex ratio 0.13 ), and the mean age of the patients was 54.24 years. The main symptom was radicular pain (92.4\%), and the average duration of the pain was 4.56 years. Spondylolisthesis predominated at the L4 - L5 level (77.97\%). Most patients (89.83\%) presented with antero-listhesis, and $110(91.53 \%)$ patients had Grade I slip. The isthmic lysis was seen in 40 patients (33.9\%). One hundred and ten patients (93.2\%) had spondylosis on digital radiography.

This study was limited to patients seen in the department of rheumatology of the Sylvanus Olympio teaching hospital; and who underwent radiography. This 
study population does not represent all patients seen in other rheumatology departments in Togo, nor patients who may be found with spondylolisthesis accidentally on radiography. Moreover, the response rate of $33.71 \%$ was low making the findings of this study not generalizable to the entire population of patients with spondylosis in Togo.

\subsection{General Characteristics of the Population}

A female predominance was noted in this study with a sex ratio (male/female) of 0.13. This sex ratio is similar to that found in Congo [8], in Cameroun [9], in South Korea [10] but is in contrast with the findings of Xao Xu et al. [11] and Michaud P. [12] that showed a male predominance. The mean age of the patients of 54.24 years in this study approximates those in the studies carried out in Cameroun [9], in Gabon [13], in China [11] [14] and is in keeping with international literature in which degenerative spondylolisthesis occurs only after the age of 40 years [6] [15]. Contrary to degenerative spondylolisthesis, patients with lumbar and sacral dysplastic anomalies present at a relatively younger age with spondylolisthesis as reported in Niger [16] and in China [17]. In these cases, there is an associated development of the lumbar lordosis in the standing position, causing the patient to find an equilibrium which at term leads to isthmic lysis and possibly to spondylolisthesis [15] [18] [19] [20].

\subsection{Clinical Semiology}

In our study, the main symptom at presentation was radicular pain which was found in $92.4 \%$ of patients. This is similar to the report by Sanoussi et al. [16] in Niger. Radicular pain is related to isthmic lysis due to the formation of lateral recess stenosis or Gill fragments [21]. In the absence of isthmic lysis, radicular pain is explained by the appearance of a narrowing of the spine [22]. The average duration of the pain in our study was 4.56 years, similar to the studies conducted in China [17] and Niger [16]. The average walking distance observed in the patients of our study was 395.29 meters. This is comparable to reports from Greece [20] and Niger [16].

\subsection{Radiographic Semiology}

Spondylolisthesis was located at the level of L4 - L5 in 77.97\% of patients in our study, and this is in keeping with findings from a similar study conducted in China [14] and in Europe [23]. These results reinforce the data from the literature on the site of spondylolisthesis [6]. In comparison, another study in China [16] found a high frequency of L5 - S1 spondylolisthesis in 59.09\% of patients. Spondylolisthesis was grade I in $91.53 \%$ of patients in our study, much higher than the 50\% reported in a study conducted in Niger [16]. These results are different from the studies of Michaud [12]; and the studies of Zhang W et al. [17], and Gelalis ID et al. [20]. These contrasts could be explained by the fact these studies were carried out in the surgical departments where only patients with 
high grades spondylosis were assessed for surgical intervention. The isthmic lysis was notified in $33.9 \%$ of the patients of our study. Degenerative spondylolisthesis is found $93.22 \%$ patients. These results are close to those of the studies carried out in Seoul [10].

\section{Conclusion}

This study shows that spondylolisthesis is a common pathology in rheumatological practice in Lomé and is most often responsible of radicular pain. Its clinical features were noted in the fifties years and affected most females. Spondylolisthesis is mainly located in the L4 - L5 stage with a predominance of Grade I. The isthmic lysis, commonly found at the fourth lumbar vertebra is rare with spondylolisthesis.

\section{Conflicts of Interest}

The authors declare no conflict of interest regarding the publication of this paper.

\section{References}

[1] Fredrickson, B.E., Baker, D., McHolick, W.J., Yuan, H.A. and Lubicky, J.P. (1984) The Natural History of Spondylolysis and Spondylolisthesis. The Journal of Bone and Joint Surgery, 66, 699-707. https://doi.org/10.2106/00004623-198466050-00008

[2] Runge, M. (1998) Lumbar Spine, Anatomical Data. Encycl. Med. Chir. (Paris, France), Radiodiagnosis I, 30650 A1012-1988, 8 p.

[3] Chan, A.K., Sharma, V., Robinson, L.C. and Mummaneni, P.V. (2019) Summary of Guidelines for the Treatment of Lumbar Spondylolisthesis. Neurosurgery Clinics of North America, 30, 353-364. https://doi.org/10.1016/j.nec.2019.02.009

[4] Hu, S.S., Tribes, C.B., Diab, M. and Ghanayen, A.J. (2008) Spondylolisthesis and Spondylolsis. The Journal of Bone and Joint Surgery. American Volume, 90, 656671.

[5] Oniankitan, O., Magnan, A., Fianyo, E. and Mijiyawa, M. (2007) The Lumbar Canal Narrowed in a Rheumatological Consultation in Lome (TOGO). Medecine Tropicale, 67, 263-266.

[6] Taillard, W.F. (1976) Aetiology of Spondylolisthesis. Clinical Orthopaedics and Related Research, 117, 30-39. https://doi.org/10.1097/00003086-197606000-00004

[7] Meyerding, H.W. (1932) Spondylolisthesis. Surgery, Gynecology and Obstetrics, 54, 371-377.

[8] Lamini N'soundhat, N.E., Boukassa, L., Ngampika Tsiba, E.F., Moyikoua, R.F., Ntsiba, H. and Bileckot, R. (2019) Profil Clinique et Radiologique des Spondylolisthesis Lombaires Vus au Centre Hospitalier Universitaire de Brazzaville. European Scientific Journal, 15, 413. https://doi.org/10.19044/esj.2019.v15n30p413

[9] Fojo, T.B., Doualla, M.S., Ongolo, Z.P., Ngoufack, C., Kemta, L.F. and NgandeuSingwe, M. (2018) Spondylolisthésis lombaire: Etude mono-centrique à l'Hôpital Régional de Bertoua. Journal Africain d' Imagerie Médicale, 10, 19-20.

[10] Lee, J.H., Kim, K.T., Suk, K.S., Lee, S.H., Jeong, B.O., Kim, J.S., Eoh, J.H. and Kim, Y.J. (2010) Analysis of Spinopelvic Parameters in Lumbar Degenerative Kyphosis: Correlation with Spinal Stenosis and Spondylolisthesis. Spine (Phila Pa 1976), 35, 
E1386-E1391. https://doi.org/10.1097/BRS.0b013e3181e88be6

[11] Xu, X., Tang, H. and Li, Z.H. (2006) Surgical Treatment of Adult Degenerative Spondylolisthesis by Instrumental Transformational Lumbar Interbody Fusion in the Han Nationality. Journal of Neurosurgery. Spine, 10, 496-499. https://doi.org/10.3171/2009.2.SPINE08623

[12] Michaud, P. (2009) Spondylolisthesis and Spinal Instability. Neurosurgery Campus. http://campus.Neurosurgery.Fr

[13] Iba, B.A.J., Mwanyombet, L., Nkoghe, D., Assengone Zeh, Y., Chouteau, P.-Y. and Loembe, P.-M. (2006) Traitement chirurgical du Spondylolisthésis au Gabon. Neurochirurgie, 52, 339-346. https://doi.org/10.1016/S0028-3770(06)71228-0

[14] Meng, C., Tang, K., Ou, Y., Quan, Z., Zhang, W., Li, Q. and Kong, X. (2010) Effectiveness of Posterior Pedicle Screw System Combined with Interbody Fusion in Treating Lumbar Spondylolisthesis. Chinese Journal of Reparative and Reconstructive Surgery, 24, 904-907.

[15] Kolbach, W. (1998) Spondylosis/Spondylolisthesis. A New Thesis of Its Aetiology. Rontgenblatter, 41, 23-26.

[16] Sanoussi, S., Bawa, M., Rabiou, M.S. and Boureima (2002) Management of Spondylolisthesis by Isthmic Lysis in Niamey, about 20 Cases. African Journal of Neurological Sciences, 27, 70-76.

[17] Zhang, W., Shang, X., Duan, L., Xu, X., Hu, Y. and Yao, G. (2010) Instrumented Slip Reduction Combined with 360 Degrees Circumferencial Fusion and Restoration of Laminae for Adult Isthmic Spondylolisthesis. Chinese Journal of Reparative and Reconstructive Surgery, 24, 1153-1158.

[18] Wiltse, L.L., Widell, E.H.J.R. and Jackson, D.W. (1975) Fatigue Fracture: The Basic Lesion in Isthmic Spondylolisthesis. The Journal of Bone and Joint Surgery, 57, 1722. https://doi.org/10.2106/00004623-197557010-00003

[19] Logroscino, G., Mazza, O., Aulisa, G., Pittal, P.E. and Aulisa, L. (2001) Spondylosis and Spondylolisthesis in Children. Child s Nervous System, 17, 644-655. https://doi.org/10.1007/s003810100495

[20] Gelalis, I.D., Arnaoutoglou, C., Christoforou, G., Lykissas, M.G., Batsilas, I. and Xenakis, T. (2010) Prospective Analysis of Surgical Outcomes in Patients Undergoing Decompressive Laminectomy and Posterior Instrumentation for Degenerative Lumbar Spinal Stenosis. Acta Orthopaedica et Traumatologica Turcica, 44, 235-240. https://doi.org/10.3944/AOTT.2010.2278

[21] Camille, R., Saillant, G., Boucher, T.H., Salgado, V. and Suarez, H. (1986) Spondylolisthesis. Sofcot Teaching Papers, 89-101.

[22] Mijiyawa, M., Oniankitan, O., Kolani, B. and Koriko, T. (2000) Low Back Pain in Hospital in Lomé (Togo). Revue du Rhumatisme, 67, 914-920. https://doi.org/10.1016/S1169-8330(00)00033-8

[23] Gille, O., Challier, V., Parent, H., Cavagna, R., Poignard, A., Faline, A., Fuentes, S., Ricart, O., Ferrero, E., Ould Slimane, M. and French Society of Spine Surgery (SFCR) (2014) Degenerative Lumbar Spondylolisthesis: Cohort of 670 Patients, and Proposal of a New Classification. Orthopaedics \& Traumatology. Surgery \& Research, 100, S311-S315. https://doi.org/10.1016/j.otsr.2014.07.006 